\title{
Urinary Tract Infections: A Comprehensive Review
}

\author{
M. Vishwanath Swamy ${ }^{1}$, Md Aqib Ali Faraz ${ }^{1}$, Sowjanya Mendem*, \\ Patil Shubham $^{1}$ and M. Vinyas ${ }^{2}$
}

\author{
${ }^{1}$ Department of Pharmacy practice, ${ }^{2}$ Department of Pharmacology, \\ MNR College of Pharmacy, Sangareddy, Telangana, India \\ *Corresponding author
}

\begin{tabular}{l} 
Ke y w o r d s \\
Urinary tract \\
infections, \\
Classification, \\
Catheter, Recurrent \\
UTIs, Bacteriruria \\
\hline Article Info \\
\hline $\begin{array}{l}\text { Accepted: } \\
\text { 08 June 2020 } \\
\text { Available Online: } \\
\text { 10 July 2020 }\end{array}$ \\
\hline
\end{tabular}

\section{A B S T R A C T}

Urinary tract infections (UTIs) are among the commonly acquired diseases in women and account for about 150 million visits annually, worldwide. These infections can be caused by several Gram-positive and Gram-negative bacteria; some of them are Escherichia coli, Klebsiella pneumoniae, Citrobacter spp., Proteus mirabilis, and Pseudomonas aeruginosa. Among Gram-positive bacteria, Staphylococcus epidermidis, Staphylococcus saprophyticus, Enterococcus species, and Serratia spp. are common and cause infections by colonizing the genitourinary tract. UTIs can be generally classified into uncomplicated and complicated infections, with the complicating infections involving the bladder, kidney, obstruction of the urinary tract, immunosuppression, etc. Uncomplicated infections present with symptoms like burning micturition, fever, flank pain, and, nausea. Risk factors for UTIs include diabetes, old age, malnutrition, immunosuppression, and, pregnancy. Diagnosis can be performed with microscopic urinalysis, dipstick analysis, and biochemical tests; however, the culture of the sample is considered to be the gold standard in the confirmation of infection. Antibiotic therapy is required in the treatment of symptomatic bacteriuria. The choice of antibiotics should be based on the culture and sensitivity profile of the organism.

\section{Introduction}

Urinary Tract Infections (UTIs) refer to the infection or inflammation caused by various bacteria or in some cases fungi to any part of the urinary tract. ${ }^{1}$ It affects about 150 million people annually worldwide and is commonly observed in clinical practice, accounting for about $10-20 \%$ and $30-40 \%$ of all infections in primary care units and hospitals respectively. Infections are more prone in the female population by 4 times than the male.
Generally, UTIs can be divided into 2 categories, namely the healthcare-associated urinary tract infection (HAUTIs) and community-associated UTIs (CAUTIs) ${ }^{2,3}$.

Even though UTIs are commonly observed, respiratory tract and gastrointestinal infections outweigh them in the population. Lower and upper UTIs are the recurring problems in women of all ages, particularly in the elderly and pregnant women of a community. 
uncomplicated UTIs account for a large proportion of infectious diseases in women. A considerable amount of antibiotics are taken regularly in community-based outpatient clinics to treat UTIs. ${ }^{5,6}$ Women in the age group of 16-64 years are at a greater risk of acquiring UTIs due to the anatomical structure of the female genitourinary system, old age, pregnancy, and personal hygiene. Pregnancy, catheter use, spinal cord injuries, diabetes impose additional risk. ${ }^{7}$

UTIs are classified into uncomplicated and complicated based on the triggering factors of the infection or the nature of the occurrence. A complicated infection of the urinary tract involves either the bladder or the kidneys, which occurs in people with functional or structural genitourinary tract abnormalities.

Symptomatic UTIs can be characterized by symptoms ranging from burning micturition to bacteremia, sepsis, and in severe cases death. ${ }^{8}$ Asymptomatic bacteriuria can be defined as the presence of significant bacteriuria without any symptoms of UTI. Symptomatic urinary tract infection can be divided into the lower tract (acute cystitis) or upper tract (acute pyelonephritis) infections.

Cystitis is a condition with significant bacteriuria and bladder mucosal invasion and pyelonephritis is where there is significant bacteriuria with inflammation of the renal parenchyma, calyces, and pelvis. ${ }^{9}$ Symptoms can range from asymptomatic bladder colonization to irritative symptoms such as urgency in micturition associated with bacterial infection; upper-tract infections are associated with fever, chills, flank pain and, serious morbidity-related bacteremia. ${ }^{10}$ Urinary tract infections are caused by Gramnegative bacteria mostly which are aerobic bacilli found in the gastrointestinal tract. Some common bacteria include Escherichia coli, Klebsiella pneumonia, Enterobacter spp., Citrobacter spp., Proteus mirabilis, and Pseudomonas aeruginosa. Among Grampositive bacteria, Staphylococcus epidermidis, Staphylococcus saprophyticus, Enterococcus species, Serratia spp. are common and result in the colonization of the genito-urinary tract leading to UTI.

The most dominant Gram-negative species causing UTI include E.coli, Klebsiella species, Proteus species, and Pseudomonas species. Staphylococcus species and Streptococcus species are commonly isolated Gram-positive bacteria. ${ }^{11}$

Diagnosis can be made by the colony count method, by which the number of viable bacterial colonies can be counted in a milliliter of the sample. It helps differentiate bacteriuria from bacterial contamination by giving a quantitative measurement. Contamination may occur during improper collection of the sample. The presence of $\geq$ $10^{5}$ colony forming units (CFUs)/ml is considered significant. ${ }^{12}$

Different broad-spectrum antibiotics are used to treat UTIs initially, although narrowspectrum antibiotics can be preferred to avoid resistance of organisms. Fluoroquinolones are generally preferred for empirical therapy of UTIs. ${ }^{13}$ This empirical therapy is initiated without the benefit of culture and sensitivity and can be deemed inappropriate as it may lead to the development of worldwide resistance of bacteria to antibiotics which may eventually give rise to the emergence of multi-drug resistant strains of bacteria. ${ }^{12}$

\section{Epidemiology of urinary tract infections}

Urinary tract infections are very frequent in women and usually occur between the age of 16 and 35 years, with $10 \%$ of women experiencing an infection yearly and nearly $40 \%$ to $60 \%$ develop an infection at least once 
in their life. Recurrences are common, and almost half of the infected population develop a second infection within a year. ${ }^{14}$ Risk factors include the genitourinary anatomy of females, increasing age, diabetes, obesity, frequent intercourse.

Uncomplicated UTIs occur with a frequency of 0.7 infections per person per year. Complicated UTI incidence is associated with risk factors, like a $10 \%$ risk exists daily of bacteriuria with an indwelling bladder catheter and up to $25 \%$ risk of it progressing to a UTI.

Bacteriuria occurs in up to $14 \%$ of diabetic women. The incidence of asymptomatic bacteriuria in pregnant women is the same as non-pregnant women $(2 \%$ to $7 \%)$ but progresses to symptomatic UTI in about $40 \%$ of pregnant women.

ASB tends to increase with age in women, reaching $80 \%$ risk in the elderly population. Patients who have undergone renal transplants are prone to UTI with $25 \%$ of them developing an infection within the first year after the transplant. ${ }^{15}$

Resistance patterns in India are greater than the other countries like the USA, UK, Australia, and South Africa. Decreased susceptibility to broad-spectrum antibiotics given as an empirical treatment can also be observed. The tendency to self-medicate, noncompliance to therapy, financial constraints, lack of education, failure to conduct surveillance of susceptibility of antibiotics, etc play a role in the increasing resistance rates to antibiotics in India. ${ }^{16}$

\section{Clinical manifestations of UTIs}

\section{Uncomplicated urinary tract infection (UTI)}

It is also known as cystitis or lower UTI and refers to the infection of the bladder and associated structures. It includes patients with no structural abnormality and no comorbidities, such as diabetes, immunodeficiency, or pregnancy. ${ }^{14}$ Uncomplicated bacterial cystitis is the most common clinical manifestation of UTI. The probability of recurrence accounts for about $20-30 \%$ in six months. ${ }^{17}$

\section{Complicated UTIs}

UTIs can have a wide range of presentations, some being simple UTIs and can be managed with outpatient antibiotics, while others may lead to florid urosepsis, which can be fatal.

Some risk factors may complicate UTIs, leading to the failure of treatment, recurring infections, and significant morbidity and mortality. Examples of a complicated UTI include:

Infections occurring due to anatomical abnormalities, for example, an obstruction, hydronephrosis, renal tract

Calculi, or colovesical fistula

Infections occurring due to an immunecompromised state, for example, steroid use, post-chemotherapy,

Diabetes, elderly population, HIV infection

Atypical organisms causing UTI

Recurrent infections despite adequate treatment (multi-drug resistant organisms)

Infections are occurring in pregnancy (including asymptomatic bacteriuria)

Infections are occurring after instrumentation, nephrostomy tubes, ureteric stents or bladder catheters

Infections in renal transplant patients

Infections are occurring in patients with impaired renal function

Infections following prostatectomies or radiotherapy. ${ }^{15}$ 


\section{Prevalent organisms causing UTIs}

Urinary tract infections are predominantly caused by the Gram-negative aerobic bacilli present in the gastrointestinal tract. The most common are: E. coli, Klebsiella pneumoniae, Enterobacter, Citrobacter, Proteus mirabilis, and $P$. aeruginosa. Other common pathogens include Staphylococcus epidermidis, Staphylococcus saprophyticus, Enterococcus species, and Serratia species which presumably result in UTI following colonization of the genito-urinary tract.

Among the most common Gram-negative bacteria include E.coli (60-70\%), Klebsiella species (10\%), Proteus species (5-10\%), and Pseudomonas species $(2-5 \%)$ are the dominant Gram-negative bacteria causing UTI. Among Gram-positive bacteria pathogens, Streptococcus spp. and Staphylococcus spp. are frequently isolated. ${ }^{11}$

The most notorious Gram-negative bacteria Escherichia coli (E.coli) are studied to be the most commonly isolated. Other Gramnegative bacteria include Acinetobacter baumannii (A.baumanni), Pseudomonas aeruginosa (P.aeruginosa), Proteus sp., Klebsiella sp., Chlamydia trachomatis, and Neisseria gonorrhea. ${ }^{19}$ Gram-positive bacteria are known to cause UTIs and include Streptococcus species(Streptococcus agalactiae (group B Streptococcus, Streptococcus pneumoniae), Staphylococcus species mainly Staphylococcus saprophyticus, Staphylococcus epidermis and Staphylococcus aureus, Enterococcus faecalis, Enterococcus faecium, Aerococcus, Corynebacterium, Actinobaculum, and Gardnerella. ${ }^{20}$

Fungi which are commonly isolated from cultures include, Candida sp., Candida albicans, Candida utilis, Candida glabrata, Candia tropicalis, Candia kefyr, and Candida guilliermondii and also the Rhodotorula sp., and Mycoplasma spp. ${ }^{19}$ Drug resistance by various microorganisms causing infectious diseases has become a global problem. This is aggravated by the increase in empirical treatments, especially in developing countries. In recent times, UTI has become more complicated and difficult to treat because of antimicrobial resistance by different organisms. $^{11}$

\section{Classification of urinary tract infections}

UTIs can be broadly classified as Symptomatic and Asymptomatic UTIs, further classification divides symptomatic UTIs into complicated and uncomplicated UTIs and asymptomatic UTIs into asymptomatic bacteriuria (Figure.1). There are a variety of non-pathogenic bacteria that can grow in the urine. In asymptomatic individuals, bacterial involvement is normal and may lead to commensal colonization of these bacteria. Asymptomatic bacteriuria can be defined as the condition with the presence of $>10^{5} \mathrm{CFU} / \mathrm{ml}$ of pathogenic bacteria, without the exhibition of any symptoms. ${ }^{21}$ Uncomplicated UTIs generally occur in previously healthy, non-pregnant women, with a normal genitourinary tract and with no recent history of instrumentation which may include bladder catheterization. ${ }^{22}$

\section{Classification of complicated UTIs}

Complicated UTI refers to a condition with a structural or a functional abnormality of the genitourinary tract, presence of comorbidities which increase the risk of severe outcomes of infection. $^{23}$

\section{Acute complicated cystitis}

Cystitis refers to the inflammation of the urinary bladder with its severity ranging from mild lower abdominal discomfort to lifethreatening hemorrhagic cystitis. 
Clinical features are characterized as a syndrome of dysuria, urgency, frequency, and lower abdominal pain. Complicated cystitis is associated with structurally or functionally abnormal urinary bladder in which the host is compromised and antimicrobial resistance develops for pathogens.

The course of the disease is mostly chronic and recurrent with urothelial dysfunction playing a key role in its mechanism. It is generally caused due to bacterial infections but can also be caused by non-infectious conditions like carcinoma in situ, bladder cancer, and bladder stone.

${ }^{24}$ Patients with complicated acute cystitis may present with atypical symptoms, for example, a patient with multiple sclerosis present with neurological deterioration and while those with spinal cord injury may present with autonomic dysfunction. $^{25}$

\section{Catheter-associated UTI}

Catheters are commonly used medical devices but have limitations as they are prone to infections. Long term or short term use of catheters may lead to an infection. Catheterassociated UTIs (CAUTIs) are the commonly studies nosocomial infections and can lead to complications like catheter encrustation, bladder stones, septicemia, endotoxic shock, and pyelonephritis.

It can be caused by either yeasts or bacteria including both Gram-negative and Grampositive bacteria.In the majority of CAUITs, E.coli is a significant source or initiator for occasional catheter users. Proteus mirabilis is the second most common CAUTI-isolated bacterial strain in patients with long term indwelling catheters.

It is not usually associated with UTI in healthy people with a functional urinary tract system, but it can, however, colonize the urinary tract of individuals with systemic or functional dysfunction. $^{26}$

\section{Complicated pyelonephritis}

Complicated pyelonephritis is a common reason for hospital admission, but the information on the epidemiology, clinical and microbiological characteristics and prognosis of complicated pyelonephritis is very limited. Acute pyelonephritis is a serious outcome of a UTI with symptoms ranging from mild discomfort to life-threatening illness or mortality, whereas complicated pyelonephritis includes the functional or anatomical abnormalities of the urinary tract.

The accurate recognition of complicated pyelonephritis is important as it is associated with complicating factors and as antimicrobial resistance is a prevailing factor, response to therapy can be disappointing. ${ }^{27}$ Complicated pyelonephritis includes patients who are pregnant, patients with uncontrolled diabetes, kidney transplants, anatomical abnormalities of the urinary tract, acute or chronic kidney disease, immunocompromised patients, or patients with nosocomial infections.

The obstruction of urine leads to incomplete emptying and urinary stasis, which causes the bacteria to multiply without being flushed out. Vesicoureteral reflux is a congenital condition that may also cause pyelonephritis by the backward flow of urine from the bladder into the kidneys. ${ }^{18}$

\section{Classification of uncomplicated UTIs}

Uncomplicated UTIs commonly occur in sexually active women, compared to elderly or pregnant women. Over the past years, the diagnostic criteria, bacterial resistance patterns and treatment recommendations have changed. $^{28}$ 


\section{Acute uncomplicated cystitis}

Cystitis is the infection of the lower urinary tract, particularly the urinary bladder. Uncomplicated cystitis affects the lower urinary tract of otherwise healthy patients without any other comorbidity. E.coli is the most prominent organism, but cystitis can also be caused by Enterobacter, Citrobacter, Serratia, Pseudomonas, Enterococci, Staphylococci, and even some fungi.

Cystitis develops due to the colonization of the periurethral mucosa by the infecting organisms from the fecal or the vaginal flora. Invasion of the urinary tract by these organisms takes place after they escape the host defenses by exhibiting certain virulence factors. Common symptoms include dysuria, urinary frequency, urgency, suprapubic pain, tenderness, and sometimes hematuria. Symptoms are subtle in the young and atypical in elderly patients. Elderly patients may also present with confusion or altered mental status. ${ }^{25}$

\section{Uncomplicated pyelonephritis}

Acute pyelonephritis is an infectious condition leading to the inflammation of the kidneys and occurs as a complication of an ascending UTI and spreads from the bladder to the kidneys and its collecting systems. Symptoms include fever, flank pain, nausea, burning micturition, etc.

Gram-negative bacteria, particularly E.coli is the main cause, along with Proteus, Klebsiella, and Enterobacter spp. Infection occurs through either the hematogenous spread or through ascending of the infection from the lower urinary tract. Hematogenous spread is less common and occurs due to urethral obstruction in immunocompromised patients; however, infection ascending from the lower urinary tract is more common. ${ }^{18}$

\section{Risk factors for developing a UTI}

European association of urology introduced a new categorization of risk factors for UTIs, known as the ORENUC system (Table 1). The known risk factors to cause UTIs can include:
old age
immune deficiency
malnutrition
obesity
diabetes mellitus
smoking
hypoalbuminemia

Preoperative bacteriuria, urethral catheter, stones in the urinary tract, and a history of previous urogenital infections are also considered as specific risk factors for UTIs. ${ }^{30}$

\section{Pathophysiology of UTIs}

UTI typically begins with contaminating the periurethral region by the uropathogens present in the gut, which eventually leads to colonization of the urethra and the urinary bladder. Subsequent host-pathogen interactions determine the colonization of the pathogen in the bladder.

Bacteria adhere to the receptors present on the bladder epithelium or the uroepithelium and mediate colonization. The pathogens invade this bladder epithelium, produce toxins and proteases which degrade the host cells, releasing nutrients, synthesizing siderophores obtaining iron.

This survival of the pathogens in the epithelia is due to the presence of structures like pili or adhesins which help in colonization. Eventually, these pathogens access the bloodstream by crossing the tubular epithelial barrier which initiates bacteremia. Pathogens like E.coli, K.pneumoniae, and $S$. saprphyticus bind to the bladder epithelium, 
which is composed of umbrella cells or the superficial facet cells, intermediate cells, and basal cells causing uncomplicated UTI. Uroplakins are the major protein components of the umbrella cell apical membrane that protect the mammalian bladder tissue from the damaging components of the urine by forming a crystalline array.

Complicated UTIs are caused when the bacteria bind to a catheter, kidney stone, or a bladder or when they are retained in the urinary tract by an obstruction. Pathogens that primarily cause complicated UTIs include P.mirabilis, P.aeruginosa, and Enterococcus spp., whereas, some pathogens like E.coli cause both complicated and uncomplicated UTIs. $^{31}$

Sexual intercourse may cause UTIs as it promotes the migration of bacteria into the bladder. Frequent voiding of the bladder lowers the risk of infection. As urine is an ideal medium for bacterial growth, factors like a $\mathrm{pH}$ less than 5 , the presence of organic acids, and high levels of urea prevent the growth of bacteria. ${ }^{14}$

Colonization of bacteria is opposed by certain host factors like acidic $\mathrm{pH}$, normal vaginal flora, and type-specific cervicovaginal antibodies. The urethra and the ureterovesicle junction are mechanical barriers that prevent the ascension of bacteria. The bladder has certain mechanisms to prevent bacteriuria.

The Mucopolysaccharide layer covering the bladder epithelium prevents colonization.

Components of uromucoid TammHorsfall protein adhere to P-fimbria and prevent colonization.

Prevention of stasis of urine and colonization by urine flow and bladder contraction.
Factors like high osmolality, high ammonium concentration, presence of phagocytes, and high urine flow rate also prevent renal infection. ${ }^{32}$

\section{Diagnosis of urinary tract infection}

Laboratory diagnosis of UTI can be done by Dipstick analysis, biochemical tests, microscopy, Gram staining, and urine culture technique. $^{33}$

\section{Dipstick analysis}

Dipsticks are the most commonly used devices when clinical evidence exists that a patient is suffering from UTIs. Multiparameter dipsticks are used mostly, which can detect nitrite, leukocyte esterase, glucose, protein, and blood, which are significant in the detection of an infection. ${ }^{34}$ This test is reportedly less expensive and an alternative for rapid assessment of biochemical parameters. The accuracy of these tests is not determined. It detects the positive value of nitrite and leukocyte esterase, which indicate the presence of bacteria and white blood cells (WBCs) in the urine respectively. Most bacteria reduce nitrates present in the urine to nitrites which can be detected by dipsticks. ${ }^{35}$

\section{Microscopic urinalysis}

Microscopy of urine is performed with manual or automated light microscopy and can help detect pyuria (> 5-10 leukocytes/HPF) and bacteriuria $(\geq 15$ bacteria/HPF). Pyuria and bacteriuria determine the presence of an infection but with varying sensitivity and specificity. Hematuria may also be indicative of an infection while WBC casts indicate upper urinary tract inflammation. The presence of squamous epithelial cells may indicate contamination. $^{36}$ 


\section{Gram's staining}

A smear of the isolate on a clean glass slide can be made, which is then air-dried and heatfixed by placing the glass slide over flame gently and Gram-stained in the end. This slide can be observed under a microscope that exhibits the staining of the bacteria. Grampositive bacteria are stained purple, whereas Gram-negative bacteria are stained pink. ${ }^{37}$

\section{Biochemical tests for identification}

Biochemical tests can be used for the identification of various organisms by routine tests like carbohydrate fermentation, methyl red, citric acid utilization, hydrogen sulfide, etc. These tests require less amount of time to identify, along with decreased cost with the accuracy in the identification of microbes. ${ }^{38}$

\section{Urine culture}

Urine culture technique is considered the gold standard for the diagnosis of a urinary tract infection but is time-consuming and tedious. It either yields positive results i.e $>10^{5} \mathrm{CFU} /$ $\mathrm{mL}$, or negative results. Lower counts of bacteria may be considered significant in elderly and immunocompromised patients as it may lead to an infection.

${ }^{35}$ The culture of the urine is considered appropriate to detect asymptomatic bacteriuria during pregnancy. The samples of urine are generally collected through a clean catch of midstream urine, but catheterized specimens can also be obtained in some cases. The culture test of urine confirms the causative organism and its susceptibility to antimicrobials. $^{36}$

\section{Prevention of recurrent Urinary tract infections}

Both antimicrobial and non-antimicrobial regimen can be used in preventing UTIs.

\section{Vaginal estrogen}

Low Estrogen levels in elderly women are observed to contribute to UTI risk. Use of vaginal Estrogen as a cream or a pessary can significantly decrease the risk. Estrogen is studied to maintain normal vaginal $\mathrm{pH}$, vaginal flora, and urinary continence.

\section{Probiotics}

Probiotics may help prevent UTIs by restoring the normal vaginal flora particularly the Lactobacillus spp. However further studies are required to support the evidence of probiotics in preventing UTIs.

\section{Cranberries}

Cranberries produce proanthocyanidins which are thought to inhibit E.coli from adhering to the bladder wall. The recommended amount of cranberry juice is $300 \mathrm{~mL}$ daily; however, tablets and capsules may also be ingested. Further research is required for optimal dosing and prevention of UTIs by cranberries.

\section{D-Mannose}

D-Mannose is observed to interfere with the adhesion of E.coli to the urothelium, hence preventing cystitis. Additional studies are needed before the recommendation for use. ${ }^{22}$

\section{Non-steroidal anti-inflammatory drugs (NSAIDs)}

Inflammatory reactions during an infection produce the symptoms of UTI. Clinical symptoms are strongly associated with the prostaglandin levels and hence, NSAIDs can inhibit the biosynthesis of prostaglandins, alleviating the symptoms. 
Table.1 ORENUC system of classification of risk factors for UTIs $\mathrm{RF}=$ risk factor

\begin{tabular}{|c|c|c|}
\hline Type & Category of risk factor & Examples of risk factors \\
\hline $\mathbf{O}$ & No known/associated RF & Healthy premenopausal women \\
\hline $\mathbf{R}$ & Recurrent UTI, but no risk of severe outcome & $\begin{array}{l}\text { Sexual behavior and } \\
\text { contraceptive devices } \\
\text { Hormonal deficiency in post } \\
\text { menopause } \\
\text { Secretory type of certain blood } \\
\text { groups } \\
\text { Controlled Diabetes mellitus }\end{array}$ \\
\hline $\mathbf{E}$ & $\begin{array}{l}\text { Extra-urogenital RF, with the risk of more } \\
\text { severe outcome }\end{array}$ & $\begin{array}{l}\text { Pregnancy } \\
\text { Male gender } \\
\text { Badly controlled diabetes } \\
\text { mellitus } \\
\text { Relevant immunosuppression } \\
\text { Connective tissue diseases } \\
\text { Prematurity of newborn }\end{array}$ \\
\hline $\mathbf{N}$ & $\begin{array}{l}\text { Nephropathic diseases, with a risk of more } \\
\text { severe outcome }\end{array}$ & $\begin{array}{l}\text { Relevant renal insufficiency } \\
\text { Polycystic nephropathy }\end{array}$ \\
\hline $\mathbf{U}$ & $\begin{array}{l}\text { Urological RF, with a risk of a severe } \\
\text { outcome, which can be resolved during } \\
\text { therapy }\end{array}$ & $\begin{array}{l}\text { Ureteral obstruction (i.e stones, } \\
\text { stricture) } \\
\text { Transient short-term urinary tract } \\
\text { catheter } \\
\text { Asymptomatic bacteriuria } \\
\text { Controlled neurogenic bladder } \\
\text { dysfunction } \\
\text { Urologic surgery }\end{array}$ \\
\hline $\mathbf{C}$ & $\begin{array}{l}\text { Permanent urinary Catheter and non- } \\
\text { resolvable urological RF, with a risk of more } \\
\text { severe outcome }\end{array}$ & $\begin{array}{l}\text { Long-term urinary tract catheter } \\
\text { treatment } \\
\text { Non-resolvable urinary } \\
\text { obstruction } \\
\text { Badly controlled neurogenic } \\
\text { bladder }\end{array}$ \\
\hline
\end{tabular}


Table.2 The treatment regimen for Urinary tract infections according to ICMR

\begin{tabular}{|c|c|c|c|c|}
\hline $\begin{array}{c}\text { Clinical } \\
\text { conditions }\end{array}$ & $\begin{array}{l}\text { Common } \\
\text { pathogens }\end{array}$ & Empiric AMA & Alternate AMA & Comments \\
\hline Acute Cystitis & $\begin{array}{c}\text { E.coli, } \\
\text { Proteus sp, } \\
\text { Klebsiella sp. }\end{array}$ & $\begin{array}{l}\text { Nitrofurantoin } 100 \mathrm{mg} \text { BD for } \\
7 \text { days } \\
\text { Cotrimoxazole } 500 / 125 \mathrm{mg} \\
\text { BD for } 3-5 \text { days } \\
\text { Ciprofloxacin } 500 \mathrm{mg} \text { BD for } \\
\text { 3-5 days }\end{array}$ & $\begin{array}{l}\text { Cefuroxime } 250 \mathrm{mg} \\
\mathrm{BD} \text { for } 3-5 \text { days } \\
\text { Cefixime } 400 \mathrm{mg} \mathrm{BD} \\
\text { for } 5 \text { days }\end{array}$ & $\begin{array}{l}\text { The duration of } \\
\text { treatment is longer } \\
\text { in pregnant women. }\end{array}$ \\
\hline $\begin{array}{c}\text { Acute } \\
\text { pyelonephritis }\end{array}$ & $\begin{array}{l}\text { E.coli, } \\
\text { Klebsiella sp, } \\
\text { Proteus sp, } \\
\text { S.aureus }\end{array}$ & $\begin{array}{l}\text { Piperacillin tazobactam } 4.5 \mathrm{gm} \\
\text { IV } 6 \text { hourly for } 10 \text { days } \\
\text { Ertapenem } 1 \mathrm{~g} \text { IV OD for } 7 \\
\text { days }\end{array}$ & $\begin{array}{l}\text { Imipenem } 500 \mathrm{mg} \text { IV } 8 \\
\text { hourly for } 10 \text { days or } \\
\text { Inj Amikacin } 5 \mathrm{mg} / \mathrm{kg} \\
\text { IV once daily for } 10 \\
\text { days }\end{array}$ & $\begin{array}{l}\text { Urine and blood } \\
\text { culture are to be } \\
\text { performed before } \\
\text { starting the } \\
\text { treatment. } \\
\text { Amikacin } 1 \mathrm{gm} \text { OD } \\
\text { IV or Gentamicin } 7 \\
\text { mg/kg as prescribed } \\
\text { doses. A close } \\
\text { monitor on renal } \\
\text { parameters is } \\
\text { needed. }\end{array}$ \\
\hline
\end{tabular}

The above table describes the suggested AMA (anti-microbial agents) for the treatment of Uncomplicated UTIs by ICMR (Indian Council of Medical Research)

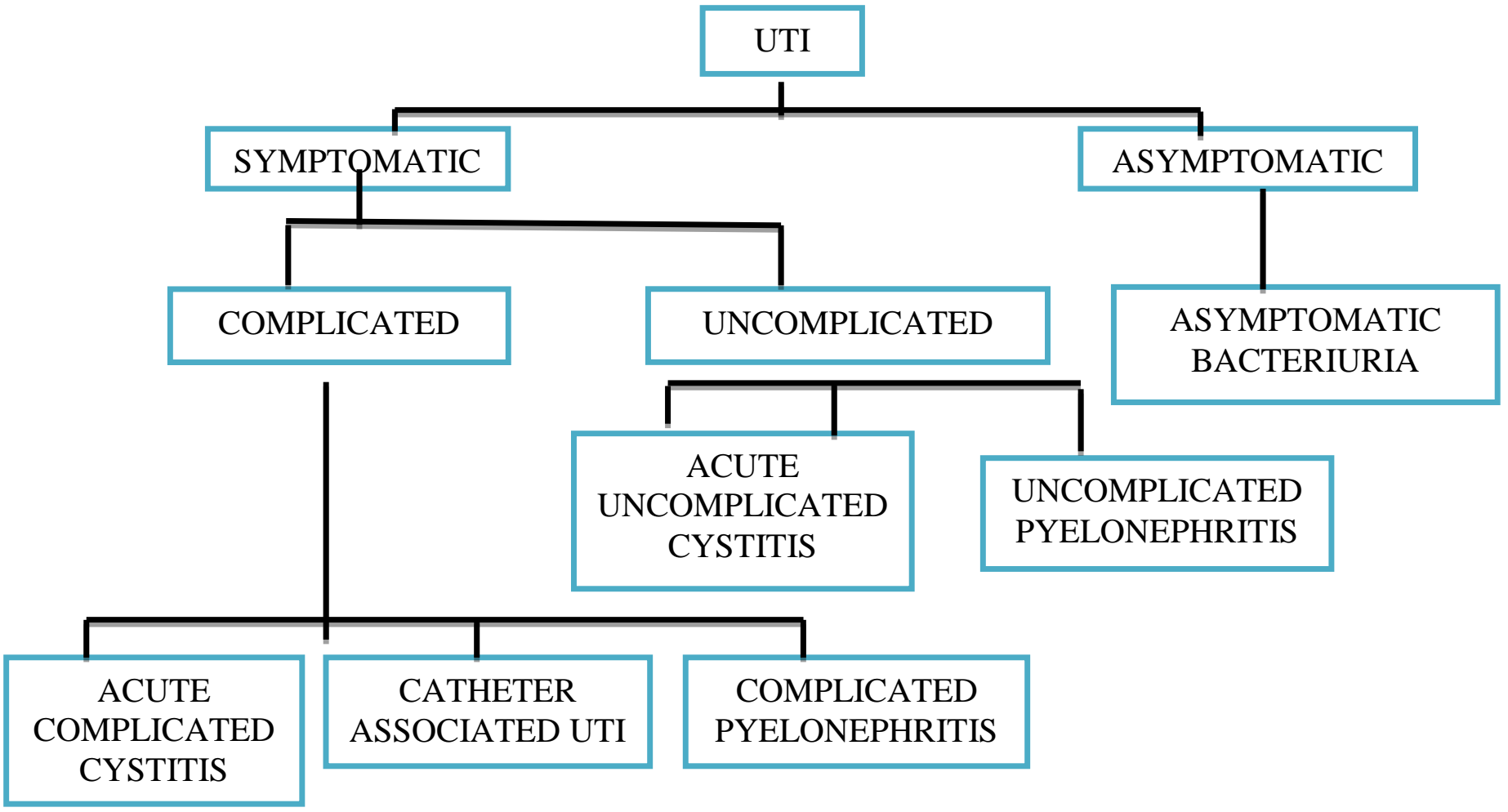

Figure.1 Classification of Urinary tract infections 


\section{Vitamins}

Vitamin C is often prescribed for RUTIs for prophylaxis. It is thought to play a role in the acidification of urine and the bacteriostatic effect by the reduction of urinary nitrates. Vitamin D is also prescribed as a supplement for the prevention of RUTIs. It is thought to induce innate antibacterial responses. ${ }^{3}$

In addition to these, hygienic practices must be followed as RUTIs are significant in improper wash and sanitation practices. Hence, education on genital and hygienic practices is important to avoid uropathogens and vaginal infections. ${ }^{39}$

\section{Treatment of urinary tract infections}

Various factors are to be considered while selecting an antibiotic regimen for UTIs. Initially, a distinction between asymptomatic and symptomatic bacteriuria is to be made. ASB is common with increasing age and may not always necessitate treatment, excluding conditions like pregnancy. ASB is associated with an increased risk of pyelonephritis and serious outcomes in pregnancy.

Antibiotic therapy is required in the treatment of symptomatic bacteriuria. The choice of antibiotics should be based on the culture and sensitivity profile of the organism. Trimethoprim-sulfamethoxazole, though popular earlier, has limited use due to increasing resistance.

Quinolones are popular in the treatment of UTIs and are indicated at higher doses for the treatment of complicated UTIs. Aminoglycosides and carbapenem are the drugs of choice in case of resistance to quinolones. Persistence or recurrence (within 2 weeks) of the infection, suggests the need for another antimicrobial based on the susceptibility profile and culture. ${ }^{40}$
Beta-lactam and fluoroquinolones are recommended for use in complicated cystitis. Quinolones are chosen popularly due to ease of availability and better clinical outcomes in most cases, with Ciprofloxacin being the most common drug of this class. Beta-lactams with combinations of $\beta$-lactic/ $\beta$-lactamase inhibitors were reported to be one of the most common drugs for the treatment of UTI. ${ }^{41}$

\section{Empirical treatment}

An empirical approach is considered appropriate for community-acquired UTI in the absence of complicating factors. First-line choice: single-dose of fosfomycin trometamol $3 \mathrm{~g}$, pivmecillinam 400mg for three days or Nitrofurantoin macro crystals $100 \mathrm{mg}$ BD for five days. ${ }^{40} \mathrm{~A}$ treatment regimen describing the suggested Anti-microbial Agents for Uncomplicated Urinary Tract Infections is described in Table. 2.

\section{Treatment of recurrent UTIs}

Antibiotic prescription is to be based on the susceptibility patterns of the organisms, the concentration of pathogens in urine, and the urinary complaint. Dose modifications may be required in patients with renal insufficiency, pregnancy, lactation, hospitalized patients, diabetes, liver diseases, immunocompromised state, etc. A 5-day course of Nitrofurantoin or a 3-day TMPSMX is recommended. Beta-lactam course of 3 to 7 days, with Amoxicillin/Clavulanic acid, is appropriate when the first-line drugs cannot be used. Fluoroquinolones are used in women experiencing allergic reactions or low tolerance after empirical treatment. Pivmecillinam for 3-7 days is also effective, but the use is limited due to its availability. Prophylaxis is highly recommended in RUTIs, usually, low dose antibiotics can be given for 6 months or more on alternate nights or 3 nights a week. ${ }^{29}$ 


\section{References}

1. Magale HI, Kassim IA, Odera SA, Omolo MJ, Jaoko WG, Jolly PE. Antibiotic susceptibility of organisms causing urinary tract infection in patients presenting at Kenyatta national hospital, Nairobi. East African medical journal. 2015; 92(7):333-337.

2. Prakash D, Saxena RS. Distribution and antimicrobial susceptibility pattern of bacterial pathogens causing urinary tract infection in the urban community of Meerut city, India. ISRN Microbiol. 2013; 749629.

3. Wawrysiuk S, Naber K, Rechberger T, Miotla P. Prevention and treatment of uncomplicated lower urinary tract infections in the era of increasing antimicrobial resistance-non-antibiotic approaches: a systemic review. Arch Gynecol Obstet. 2019; 300:821828.

4. Nimri L. Community-acquired urinary tract infections in a rural area in Jordan: Predominant uropathogens, and their antimicrobial resistance. WMC Micro bio2010;1(9): WMC00660.

5. Lee DS, Lee SJ, Choe HS. Communityacquired urinary tract infection by Escherichia coli in the era of antibiotic resistance. BioMed res intl. 2018; 7656752.

6. Ny S, Edquist P, Dumpis U, GröndahlYli-Hannuksela K, Hermes J, Kling AM, Klingeberg A, Kozlov R, Källman O, Lis DO, Pomorska-Wesołowska M. Antimicrobial resistance of Escherichia coli isolates from outpatient urinary tract infections in women in six European countries including Russia. J Glob Antimicrob Re. 2019; 17:25-34.

7. Chandra Bala Sekharan, Koneru Ratna Kumari, Evod Ernest Kuwingwa, Kumar DD. Evaluation of the Prevalence of Urinary Tract Infection in females Aged
6-50 Years at Kinondoni District, Tanzania. Sci Int.,5:42-46.

8. Muthulakshmi M, Gopalakrishnan S. Study on urinary tract infection among females of reproductive age group in a rural area of Kancheepuram district, Tamil Nadu. Int $\mathbf{J}$ Community Med Public Health. 2017; 4(10):3915-3921.

9. Schnarr J, Smaill F. Asymptomatic bacteriuria and symptomatic urinary tract infections in pregnancy. Eur J Clin Invest 2008; 38 (S2): 50-57.

10. Geetika Arora, Parminder Kaur, Divya Agrawal, Urinary tract infection in women of the rural population of Haryana: a rising problem, IJRCOG, 2016; 5(12):4470-4474.

11. Gessese YA, Damessa DL, Amare MM, Bahta YH, Shifera AD, Tasew FS, Gebremedhin EZ. Urinary pathogenic bacterial profile, antibiogram of isolates and associated risk factors among pregnant women in Ambo town, Central Ethiopia: a cross-sectional study. Antimicrob Resist In. 2017; 6(1):132142.

12. Ahmed SS, Shariq A, Alsalloom AA, Babikir IH, Alhomoud BN. Uropathogens and their antimicrobial resistance patterns: Relationship with urinary tract infections. IJHS. 2019; 13(2):48-55.

13. Akram M, Shahid M, Khan AU. Etiology and antibiotic resistance patterns of community-acquired urinary tract infections in JNMC Hospital Aligarh, India. Ann Clin Microbiol Antimicrob. 2007; 6(1):4-10.

14. Bono MJ, Reygaert WC. Urinary tract infection. InStatPearls [Internet] 2019 Dec 2. StatPearls Publishing.

15. Sabih A, Leslie SW. Complicated urinary tract infections. InStatPearls [Internet] 2019 Mar 5. StatPearls Publishing.

16. Patel HB, Soni ST, Bhagyalaxmi A, Patel NM. Causative agents of urinary tract 
infections and their antimicrobial susceptibility patterns at a referral center in Western India: An audit to help clinicians prevent antibiotic misuse. J Family Med Prim Care. 2019; 8(1):154159.

17. Hibbing ME, Conover MS, Hultgren SJ. The unexplored relationship between urinary tract infections and the autonomic nervous system. Auton Neurosci.. 2016; 200:29-34.

18. Belyayeva M, Jeong JM. Acute pyelonephritis. 2019 Feb: StatPearls [Internet]. Treasure Island (FL): StatPearls Publishing.

19. Mishra MP, Debata NK, Padhy RN. Surveillance of multidrug resistant uropathogenic bacteria in hospitalized patients in Indian. Asian Pac J Trop Biomed 2013; 3(4): 315-324.

20. Kline KA, Lewis AL. Gram- positive uropathogens, polymicrobial urinary tract infection, and the emerging microbiota of the urinary tract. Microbiol Spectr. 2016 ; 4(2): 459-502.

21. Smelov V, Naber K, Johansen TE. Improved classification of urinary tract infection: future considerations. Eur. Urol. Suppl. 2016; 15(4):71-80.

22. Kolman KB. Cystitis and pyelonephritis: diagnosis, treatment, and prevention. Prim Care Clin Office Pract 46 2019; 191-202.

23. Tan CW, Chlebicki MP. Urinary tract infections in adults. Singapore Med J 2016; 57(9): 485-490.

24. Lee G, Romih R, Zupančič D. Cystitis: from urothelial cell biology to clinical applications BioMed res intl. 2014; 473536.

25. Li R, Leslie SW. Cystitis. InStatPearls [Internet] 2019. StatPearls Publishing.

26. Cortese YJ, Wagner VE, Tierney M, Devine D, Fogarty A. Review of catheter-associated urinary tract infections and in vitro urinary tract models. J Healthc Eng 2018; 2986742.

27. Buonaiuto VA, Marquez I, De Toro I, Joya C, Ruiz-Mesa JD, Seara R, Plata A, Sobrino B, Palop B, Colmenero JD. Clinical and epidemiological features and prognosis of complicated pyelonephritis: a prospective observational single hospital-based study. BMC Infect Dis. 2014;14(1):639-646.

28. Mehnert-Kay SA. Diagnosis and management of uncomplicated urinary tract infections Am Fam Physician. 2005; 72(3):451-456.

29. Al-Badr A, Al-Shaikh G. Recurrent urinary tract infections management in women: a review. Sultan Qaboos Univ. Med. J. 2013; 13(3):359-367.

30. Junuzovic D, Hasanbegovic M. Risk Factors analysis for the occurrence of asymptomatic bacteriuria after endourological procedures. Med Arch. 2014; 68(4): 249-253.

31. Flores-Mireles AL, Walker JN, Caparon M, Hultgren SJ. Urinary tract infections: epidemiology, mechanisms of infection, and treatment options. Nat. Rev. Microbiol. 2015; 13(5):269-284.

32. Najar MS, Saldanha CL, Banday KA. Approach to urinary tract infections. Indian J Nephrol. 2009 Oct; 19(4): 129139.

33. Dadzie I, Quansah E, Puopelle Dakorah M, Abiade V, Takyi-Amuah E, Adusei R. The Effectiveness of Dipstick for the Detection of Urinary Tract Infection. Can J Infect Dis Med Microbiol. 2019; 8642628 .

34. Schmiemann G, Kniehl E, Gebhardt K, Matejczyk MM, Hummers-Pradier E. The diagnosis of urinary tract infection: a systematic review. Dtsch Arztebl Int. 2010; 107(21):361-367.

35. Marques AG, Pasternak J, Damascena MD, França CN, Martino MD. Performance of the dipstick screening test as a predictor of negative urine culture. 
Einstein (São Paulo). 2017(1):34-39.

36. Chu CM, Lowder JL. Diagnosis and treatment of urinary tract infections across age groups. Am J Obstet Gynecol. 2018; 219(1):40-51.

37. Simon-Oke IA, Odeyemi O, Afolabi OJ. Incidence of urinary tract infections and antimicrobial susceptibility pattern among pregnant women in Akure, Nigeria. Scientific African. 2019; 6: $\mathrm{e} 00151$.

38. Zhou X, Li Y, editors. Atlas of Oral Microbiology: From Healthy Microflora to Disease. Academic Press; 2015.

39. Mohanty JR, Pradhan A, Jena S, Misra PR, Padhi B, Soren D. Hygiene and Wash Practices Associated with Urinary
Tract Infection among Non-Pregnant Women at Capital Hospital, Bhubaneswar, Odisha, India. Int. J. Curr. Microbiol. App. Sci. 2018;7(3):17431753.

40. Minardi D, D'Angelo G, Cantoro D, Conti A, Muzzonigro G. Urinary tract infections in women: etiology and treatment options. Int. J. Gen. Med. 2011;4:333-343.

41. Lakhani JD, Lakhani SJ, Meera S, Sanket P, Sandeep J. Appropriate use of antimicrobial agents in urinary tract infections: Perception of physicians and resident doctors. J Integr Health Sci 2019; 7:19-24.

\section{How to cite this article:}

Vishwanath Swam. M., Md Aqib Ali Faraz, Sowjanya Mendem, Patil Shubham and Vinyas. M. 2020. Urinary Tract Infections: A Comprehensive Review. Int.J.Curr.Microbiol.App.Sci. 9(07): 773-786. doi: https://doi.org/10.20546/ijcmas.2020.907.089 